\title{
A Família e o Reconhecimento de Paternidade Socioafetiva no Ordenamento Jurídico Brasileiro
}

\section{Recognition of Socio-Affective Paternity in the Brazilian Legal System}

\author{
Juliana Isabele Gomes Probst*ab; Vitor Ferreira de Campos ${ }^{\mathrm{c}}$ \\ aUnopar, Programa de Pós-Graduação Stricto Sensu em Metodologias para o Ensino de Linguagens e suas Tecnologias. PR, Brasil. \\ 'Instituto Infnet - Faculdade de Tecnologia, Curso de Análise de Desenvolvimento de Sistemas. RJ, Brasil. \\ ${ }^{\mathrm{c} C o g n a}$ Jurídico, Coordenação de Área em Ciências Sociais Aplicadas. PR, Brasil. \\ *E-mail: probst.julianaig@gmail.com.br.
}

\begin{abstract}
Resumo
Entre os destaques relacionados ao Direito de Família se encontra, em sua própria titulação, o cerne de todas as discussões dessa decorrentes: a concepção de família. Como uma das ramificações dessa concepção, fruto da nova interpretação sobre o conceito de família, a filiação deixou de ter relação apenas com a consanguinidade, mas adentrou ao âmago das relações sociais de afeto. Compreender a evolução do conceito de família nuclear, suas novas estruturações na contemporaneidade, o conceito de socioafetividade e sua composição no ordenamento jurídico brasileiro é exordio para a apreensão da concepção teórica do Direito de Família em sentido macro, exigindo uma análise aprofundada das transformações decorrentes das vicissitudes do cenário global constituinte das relações e manifestações sociais, geopolíticas e econômicas, bem como um estudo comparado entre teoria e prática. Por meio da pesquisa qualitativa bibliográfica é possível analisar o Direito de Família, sobretudo, no que tange ao reconhecimento de paternidade socioafetiva, tendo por base julgados e legislações contemporâneas, trazendo segurança jurídica na adoção desta prática interpretativa do Direito, que ainda causa dúvidas e controvérsias ideológicas, as quais nos últimos anos têm sido alvo de debates, de reflexões, de avanços e de retrocessos, como todo bom processo de evolução na sociedade.
\end{abstract}

Palavras-chave: Paternidade Socioafetiva. Direito de Família. Conceito de Família.

\begin{abstract}
Among the highlights related to Family Law, there is in its own title the heart of all discussions arising from it: the family concept. As one of the ramifications of this conception, the result of the new family concept interpretation, affiliation is no longer related only to consanguinity, but has entered the heart of social relationships of affection. Understanding the evolution of the nuclear family concept, its new structures in contemporary times, the socio-affectivity concept and its composition in the Brazilian legal system, is a requirement for understanding the theoretical conception of Family Law in a macro sense, requiring an in-depth analysis of the transformations arising out of the vicissitudes of the global scenario constituting the social, geopolitical and economic relations and manifestations, as well as a comparative study between theory and practice. Through qualitative bibliographic research, it is possible to analyze Family Law, especially regarding the recognition of socio-affective paternity, based on contemporary judgments and legislation, bringing legal certainty in the adoption of this interpretative Law practice, which still causes doubts and ideological controversies, which in recent years has been the subject of debates, reflections, advances and setbacks, like any good evolution process in the society.
\end{abstract}

Keywords: Socio-Affective Fatherhood. Family Right. Family Concept.

\section{Introdução}

Os reflexos das nuances da sociedade no contexto do capitalismo ideológico neoliberal do século XXI inferem diretamente no paradigma da ordem social e jurídica.

O Estado Democrático de Direito, atrelado à concepção de ampliação e consolidação de direitos, combatido pelo Neoliberalismo, vive uma nova era no Direito Civil, sobretudo, no Direito de Família que sofreu forte influência pelos pensamentos de garantia de direitos individuais e coletivos, especialmente, no âmbito dos Direitos Humanos, o qual busca alargar suas esferas e garantir amplitude de cobertura jurídicosocial.

Sobre este pensamento se tem que com o passar dos séculos, novos pensamentos políticos, sociais e econômicos foram formados, o que exigiu do Direito adequações e revisões. E, com o Direito de Família não foi diferente.

Como o próprio nome aduz, o Direito de Família se consolida pautado no conceito de família e todas as ramificações desse decorrentes.

Se, em 1916, o Código Civil considerava família aquela constituída tão somente pelo casamento, posteriormente, em 1988, ao lado do casamento houve o reconhecimento da União Estável e da família monoparental.

A nova percepção de Família do século XXI, após a Constituição de 1988, preserva ainda a pluralidade, os direitos de escolhas individuais e a garantia de direito para as mais diversas espécies de família que existem na contemporaneidade.

Nesse diapasão, o Poder Judiciário se viu impelido a arrazoar sobre a consideração afetiva em nível jurídico 
como o reconhecimento de maternidade/paternidade mesmo sem vínculo de laço sanguíneo, sendo este conhecido pela comprovação de afeto.

Pensando nestas alterações, pode-se dizer que a nova ordem jurídica reconheceu as transformações na sociedade, considerando as outras estruturas existentes que até então não eram tuteladas e resguardadas, ampliando assim a perspectiva de extensão dos direitos que acabavam por segregar essas novas formações.

Essa conjuntura analítica sobre a concepção de família, especialmente, no que tange ao reconhecimento de filiação socioafetiva na contemporaneidade, conduz a produção desta pesquisa que perpassará pela análise do contexto histórico de família e suas ramificações, pela compreensão das novas concepções de família e a estruturação do direito a paternidade socioafetiva e seus elementos constitutivos.

Depois de preliminar reflexão sobre a paternidade afetiva e seu reconhecimento no âmbito jurídico, embasarse-á a reflexão nos julgados mais recentes sobre o tema, ponderando como ocorre, na prática, a incidência jurídica do reconhecimento à socioafetividade.

\section{Desenvolvimento}

\subsection{Metodologia}

$\mathrm{O}$ artigo científico em tela tem por foco explorar a pesquisa qualitativa bibliográfica disponível em legislações, artigos, revistas e periódicos no âmbito da análise do Direito de Família, principalmente com enfoque no reconhecimento de paternidade socioafetiva.

A modalidade de pesquisa escolhida, conforme expõe Marconi e Lakatos (1992), proporciona ao pesquisador um contato direto com o material escrito sobre determinado contexto, permitindo ao pesquisador a análise e a manipulação de informações, considerada o primeiro passo para toda a pesquisa científica.

\subsection{Reflexão Analítica do Conceito de Família}

A origem da conceituação família nos remonta aos tempos romanos e gregos e tem suas bases preliminares assentadas no contexto do matrimônio, sendo vedada qualquer outra composição familiar.

Em nível brasileiro, se pensarmos na evolução interpretativa jurídica do conceito de família, pode-se inferir que o marco separatório das concepções tradicionalistas para o novo, se deu com a promulgação da Constituição Federal de 1988.

A Constituição não só ampliou as possibilidades em termos de garantia de direitos e a constituição da família, bem como concedeu margem para interpretações extensivas de família, em que o matrimônio deixa de ser o foco da análise, e sim o Estado como tutelador do Direito, independe do tipo de escolha de Constituição que o núcleo adotar.

Com a possibilidade de interpretação extensiva se impetraram novas ações e demandas ao Judiciário, que passou a olhar para a família moderna sob o prisma do que hoje se reconhece como o Art. 6 da Lei n ${ }^{\circ} 11.340 / 06$, cuja definição prevê que essa pode ser definida como uma "comunidade formada por indivíduos que são ou se consideram aparentados, unidos por laços naturais, por afinidade ou por vontade expressa; independentemente de orientação sexual" (art. 5º, inciso II, e parágrafo único).

Diniz (2017, p. 30) em análise a Constituição propõe o afeto como elemento agregador e elo fundamental na formação familiar. Para ele, a novidade legal no conceito de Família se harmoniza com o conceito de casamento entre cônjuges, previsto no art. 1.511, do Código Civil, não apenas deixando de ser oposta a questão matrimônio entre pessoas do mesmo gênero, como também explicitando que a heterossexualidade não é condição para o casamento, extinguindo a barreira formal entre uniões e democratizando o direito a essa.

Ante ao reconhecimento dos tipos de Família trazidos pelo Art. 226 da CF de 88, embora não sendo ele taxativo, cabe entendimento que famílias são

não apenas das instituídas pelo casamento, pela união estável ou pela monoparentalidade, senão também das entidades familiares formadas pela união de parentes, que vivem em interdependência entre si (MACEDO, 2012, p.12).

Lôbo (2017, p.91), ao explanar sobre o conceito de família, pondera existir três pilares basilares estruturais de família, sendo esses:

Afetividade, como fundamento e finalidade da entidade, com desconsideração do móvel econômico; Estabilidade, excluindo-se os relacionamentos casuais, episódicos ou descomprometidos, sem comunhão de vida; Ostensibilidade, o que pressupõe uma unidade familiar que se apresente assim publicamente.

Considerando a exposição de Lôbo (2017), entende-se não mais ser cabível o conceito de família nuclear tradicional como único modelo vigente, existindo diversas formações. Nessa perspectiva, Dias (2015, p.60) menciona:

[...] não há qualquer referência a determinado tipo de família, como ocorreu com as constituições brasileiras anteriores. Ao suprimir a locução 'constituída pelo casamento' (art. 175 da Constituição de 1967-69), sem substituí-la por qualquer outra, pôs sob a tutela constitucional 'a família', ou seja, qualquer família. A cláusula de exclusão desapareceu. [...] Em consequência, o caput do art. 226 é cláusula de inclusão, não sendo admissível excluir qualquer entidade que preencha os requisitos de afetividade, estabilidade e ostensibilidade. (DIAS, 2015, p. 60).

Ao se considerar, portanto, as ramificações familiares, pode-se constatar a existência da família extensa, conforme leciona o parágrafo único do art. 25 da nova Lei da Adoção (Lei $\mathrm{n}^{\mathrm{o}}$ 12.010): “entende-se por família extensa ou ampliada aquela que se estende para além da unidade pais e filhos ou da unidade do casal, formada por parentes próximos com os quais a criança ou adolescente convive e mantém vínculos de afinidade e afetividade" (BRASIL, 2009). 
Por conseguinte, encontra-se a definição de família mosaica/combinada ou também intitulada como recombinada. Esta, configura-se quando:

numa nova união conjugal ou convencional, haja descendentes de relações anteriores, de um ou dos dois cônjuges ou companheiros, inclusive sendo possível a adoção do(a) enteado(a) pelo parceiro da mãe ou pela parceira do pai, desde que haja ausência do pai ou da mãe registral (MACEDO, 2012, p.16).

Existem ainda outras três definições de família, segundo Macedo (2012), sendo essas a unitária, anaparental e eudemonista. Para o autor,

[...] a família unitária, constitui-se por um único membro, independentemente de relação conjugal ou não, porque a tutela da lei ao bem de família é concedida para proteger não a família, como elemento grupal, mas cada um dos seus membros como pessoa individualmente considerada.

[...] Já a família anaparental, caracteriza pela convivência entre parentes ou mesmo entre pessoas que não são parentes, que possuem os mesmos propósitos e se unem em razão do afeto que há entre elas. A convivência longa e duradoura sob o mesmo teto entre duas irmãs que formam um acerco patrimonial comum, ou até mesmo duas amigas idosas que resolvem viver juntas, compartilhando suas aposentadorias, são exemplos de família anaparental.

[...] $\mathrm{Na}$ família eudemonista, o foco principal é a felicidade. É uma família afetiva que se forma dentro do "entendimento de que a felicidade individual ou coletiva é o fundamento da conduta humana moral. É a família formada em busca da felicidade. A família eudemonista é um conceito moderno que se refere à família que busca a realização plena de seus membros (MACEDO, 2012, p.17-272).

Há que se considerar ainda as formações familiares formadas por casais homoafetivos, as quais se expressam como representantes da abertura do conceito de família no ordenamento jurídico brasileiro, os quais manifestam distintas visões a seu respeito.

E por fim, a família socioafetiva, que é o foco dos esforços de compreensão deste estudo, a qual tem sua constituição com base nos vínculos de afeto, superando a verdade biológica.

É cabível ressaltar que o tema família é amplo e, por si só, complexo, não sendo aqui a finalidade esgotar o tema, e sim, trazer foco à temática central do respectivo estudo, a paternidade socioafetiva.

\subsection{Da Paternidade Socioafetiva: Elementos Constitutivos}

Com notoriedade no Código Civil, no Art. 1593, a paternidade socioafetiva evidencia sua constatação a partir da demonstração de vínculo de afeto de uma pessoa em relação à outra, ligado intimamente à base do núcleo familiar.

Sobre este pilar, a filiação pode ser compreendida, portanto, em sua relação intrínseca com o afeto, afastando-se dos critérios exclusivamente biológicos naturais e genéticos, sendo associada às questões culturais e sociais.

Oliveira $(2018$, p.24) considera a paternidade socioafetiva como "a prova da força que o afeto tem na vida dos indivíduos, é o vínculo gerado entre pai e filho, independente da consanguinidade".
Em uma mesma análise, Nogueira (2015, p.119) salienta que:

O pai afetivo é aquele que cuida, educa, dá carinho, amor, está presente na vida da criança, que assume as suas responsabilidades, que age de forma efetiva com a figura do pai, é aquele em que a criança vê como o pai dela, vê nele a figura de confiança, e principalmente de afeto. Ou seja, a paternidade afetiva é uma relação construída pelo cotidiano com a criança de forma cultural e psicológica. "O pai afetivo é aquele que ocupa na vida do filho, o lugar do pai (a função). É uma espécie de adoção de fato. É aquele que ao dar abrigo, carinho, educação, amor...ao filho, expõe o fato íntimo da filiação, apresentando-se em todos os momentos inclusive naqueles em que se torna a lição de casa ou verifica o boletim escolar. Enfim, é o pai das emoções, dos sentimentos e é o filho do olhar embevecido que reflete aqueles sentimentos que sobre ele se projetam. Em suma, com base em tudo o que vimos anteriormente, entendemos que a parentalidade socioafetiva pode ser definida como o vínculo de parentesco civil entre pessoas que não possuem entre si um vínculo biológico, mas que vivem como se parentes fossem, em decorrência do forte vínculo afetivo existente entre elas.

Em termos jurídicos, a paternidade afetiva está prevista de forma implícita na Constituição Federal, no Art. 226 e no Código Civil, conforme mencionado alhures. E no ano de 2017, o Conselho Nacional de Justiça publicou o Provimento 63 (modificado pelo Provimento 83), através do qual, entre outros temas, disciplinou o procedimento de reconhecimento de filiação socioafetiva, perante os Ofícios do Registro Civil das Pessoas Naturais, conforme lê-se abaixo:

Art. $1^{\circ}$ O Provimento n. 63, de 14 de novembro de 2017 , passa a vigorar com as seguintes alterações: I - o art. 10 passa a ter a seguinte redação: Art. 10. O reconhecimento voluntário da paternidade ou da maternidade socioafetiva de pessoas acima de 12 anos será autorizado perante os oficiais de registro civil das pessoas naturais. II - o Provimento n. 63, passa a vigorar acrescida do seguinte art. 10-A: Art. 10-A. A paternidade ou a maternidade socioafetiva deve ser estável e deve estar exteriorizada socialmente. $1^{\circ} \mathrm{O}$ registrador deverá atestar a existência do vínculo afetivo da paternidade ou maternidade socioafetiva mediante apuração objetiva por intermédio da verificação de elementos concretos. $\cdot 2^{\circ}$ O requerente demonstrará a afetividade por todos os meios em direito admitidos, bem como por documentos, tais como: apontamento escolar como responsável ou representante do aluno; inscrição do pretenso filho em plano de saúde ou em órgão de previdência; registro oficial de que residem na mesma unidade domiciliar; vínculo de conjugalidade casamento ou união estável - com o ascendente biológico; inscrição como dependente do requerente em entidades associativas; fotografias em celebrações relevantes; declaração de testemunhas com firma reconhecida. $\cdot 3^{\circ} \mathrm{A}$ ausência destes documentos não impede o registro, desde que justificada a impossibilidade, no entanto, o registrador deverá atestar como apurou o vínculo socioafetivo. $\bullet 4^{\circ} \mathrm{Os}$ documentos colhidos na apuração do vínculo socioafetivo deverão ser arquivados pelo registrador (originais ou cópias) juntamente com o requerimento. III - o $\S 4^{\circ}$ do art. 11 passa a ter a seguinte redação: $\bullet 4^{\circ}$ Se o filho for menor de 18 anos, o reconhecimento da paternidade ou maternidade socioafetiva exigirá o seu consentimento. IV - o art. 11 passa a vigorar acrescido de um parágrafo, numerado como $\S 9^{\circ}$, na forma seguinte: "art. 11

- $9^{\circ}$ Atendidos os requisitos para o reconhecimento da paternidade ou maternidade socioafetiva, o registrador 
encaminhará o expediente ao representante do Ministério Público para parecer. I - $\mathrm{O}$ registro da paternidade ou maternidade socioafetiva será realizado pelo registrador após o parecer favorável do Ministério Público. II - Se o parecer for desfavorável, o registrador não procederá o registro da paternidade ou maternidade socioafetiva e comunicará o ocorrido ao requerente, arquivando-se o expediente. III Eventual dúvida referente ao registro deverá ser remetida ao juízo competente para dirimí-la. V - o art. 14 passa a vigorar acrescido de dois parágrafo, numerados como $\S 1^{\circ}$ e $\S 2^{\circ}$, na forma seguinte: "art. 14

- $1^{\text {a }}$ Somente é permitida a inclusão de um ascendente socioafetivo, seja do lado paterno ou do materno. - $2^{\circ} \mathrm{A}$ inclusão de mais de um ascendente socioafetivo deverá tramitar pela via judicial.

Art $2^{\circ}$ Este provimento entrará em vigor na data de sua publicação.

Nos termos da Lei, portanto, há o estabelecimento de critérios para o reconhecimento da filiação socioafetiva. Nesse sentido, a doutrina menciona que, no caso filiação socioafetiva, o ato só pode ser feito extrajudicialmente (em cartório de registro civil) em casos de crianças com mais de doze anos, as quais devem consentir com o ato, assim como os pais biológicos, pessoalmente. Já no caso de infantes com idade inferior a doze anos, o ato só pode ser feito por via judicial.

Nesta nova modalidade de família, que ocorre mediante processo (seja esse judicial ou extrajudicial) de análise dos vínculos, para ser considerada válida, precisa ser pública, contínua, duradoura e consolidada.

Insta salientar que o reconhecimento socioafetivo entre irmãos é vedado e que deve ser preenchido o critério de distinção de dezesseis anos entre a pessoa que irá realizar o reconhecimento e o filho a ser reconhecido, assim como em casos de adoção.

Para dar entrada no pedido extrajudicial, as partes impetrantes (pais biológicos e filhos) devem comparecer em um Cartório de Registro Civil para preenchimento de requerimento manifestando interesse, munidos de seus documentos pessoais originais com foto, a certidão de nascimento original e atualizada do filho e demais documentos comprobatórios do vínculo socioafetivo entre as partes.

No texto da lei, os requisitos para que o reconhecimento da filiação socioafetiva seja deferido extrajudicialmente são os seguintes:

I - Requerimento firmado pelo ascendente socioafetivo (nos termos do Anexo VI), testamento ou codicilo (artigo 11, parágrafos $1^{\circ}$ e $8^{\circ}$, do Provimento 63/2017 do CNJ); II Documento de identificação com foto do requerente - original e cópia simples ou autenticada (artigo 11 do Provimento 63/2017 do CNJ); III - Certidão de nascimento atualizada do filho - original e cópia simples ou autenticada (artigo 11 do Provimento 63/2017 do CNJ); IV - Anuência pessoalmente dos pais biológicos, na hipótese do filho ser menor de 18 anos de idade (artigo 11, parágrafos $3^{\circ}$ e $5^{\circ}$, do Provimento 63/2017 do CNJ); V - Anuência pessoalmente do filho maior de 12 anos de idade (artigo 11, parágrafos $4^{\circ}$ e $5^{\circ}$, do Provimento 63/2017 do CNJ); VI - Não poderão ter a filiação socioafetiva reconhecida os irmãos entre si nem os ascendentes (artigo 10, parágrafo $3^{\circ}$, do Provimento 63/2017 do CNJ); VII - Entre o requerente e o filho deve haver uma diferença de pelo menos 16 anos de idade (artigo 10, parágrafo $3^{\circ}$, do Provimento 63/2017 do CNJ); VIII - Comprovação da posse do estado de filho (artigo 12 do Provimento 63/2017 do CNJ). (BRASIL, 2017).

Em meio a esse provimento, a doutrina jurídica não corrobora com alguns pontos. Tem-se como exemplo, o apresentado pelo artigo 11, parágrafo $5^{\circ}$ onde estabelece que "a coleta da anuência tanto do pai quanto da mãe e do filho maior de doze anos deverá ser feita pessoalmente perante o oficial de registro civil das pessoas naturais ou escrevente autorizado (BRASIL, 2017).

Após abertura do processo, é de responsabilidade do Oficial do Cartório o procedimento de investigação para atestar a existência do vínculo socioafetivo e, em caso de dúvida/suspeita, poderá o Oficial exigir outros documentos ou denegar a ação. Caso reconhecido o vínculo sem impeditivos, o processo é enviado para consulta ao Ministério Público e, após isso, o novo registro é feito no próprio Cartório.

Cumpridos os requisitos, sendo deferido o reconhecimento, a Justiça determina a alteração do registro de nascimento do filho, com a inclusão do nome do pai e/ou mãe socioafetivos e o nome dos avós. Vale mencionar que o reconhecimento pode ser realizado a qualquer tempo, inclusive, após a morte dos pais, desde que evidenciada a relação entre os pares.

Dessa feita, cabe ao Oficial de registro especial estar atento à comprovação dos elementos e requisitos estipulados em lei que caracterizam a filiação socioafetiva, tornando efetiva e possível a sua consolidação, por meio de registro nos Cartórios Civil de qualquer unidade federativa, garantindo a uniformidade de procedimentos.

Nessa seara, a lei assegura que os filhos afetivos não se distinguem dos genéticos, equiparando os mesmos direitos e efeitos sucessórios (pessoais e patrimoniais) entre eles. Cabe também mencionar ainda que, no tocante à paternidade socioafetiva, essa é irrevogável, visto que o "vínculo afetivo é irretratável e irrenunciável, isto é, aquele que reconheceu como se filho fosse não pode mais romper esse vínculo depois de estabelecida a socioafetividade" (SUZIGAN, 2015, p. 15).

\subsection{Da Filiação Socioafetiva e os Postulados Judiciais}

Em estudo, nota-se que a filiação socioafetiva já está presente no regimento jurídico pátrio, não se vislumbrando nesta fase sua extinção ou desconstrução, tendo reconhecimento da própria jurisprudência que vem ao longo dos últimos anos, a qual apresenta o entendimento da possibilidade de existência da filiação socioafetiva, como se vê no julgado abaixo:

RECURSO ESPECIAL No 878.941 - DF (2006/00862840) EMENTA: RECONHECIMENTO DE FILIAÇÃO. AÇÃO DECLARATÓRIA DE NULIDADE. INEXISTÊNCIA DE RELAÇÃO SANGUÍNEA ENTRE AS PARTES. IRRELEVÂNCIADIANTE DO VÍNCULO SÓCIOAFETIVO. Merece reforma o acórdão que, ao julgar embargos de declaração, impõe multa com amparo no art. 538, par. único, CPC se o recurso não apresenta caráter modificativo e se foi interposto com expressa finalidade de pré questionar. Inteligência da Súmula 98, STJ.- O reconhecimento de paternidade é válido se reflete a existência 
duradoura do vínculo sócio-afetivo entre pais e filhos. A ausência de vínculo biológico é fato que por si só não revela a falsidade da declaração de vontade consubstanciada no ato do reconhecimento. A relação sócio-afetiva é fato que não pode ser, e não é, desconhecido pelo Direito. Inexistência de nulidade do assento lançado em registro civil.- O STJ vem dando prioridade ao critério biológico para o reconhecimento da filiação naquelas circunstâncias em que há dissenso familiar, onde a relação sócio-afetiva desapareceu ou nunca existiu. Não se pode impor os deveres de cuidado, de carinho e de sustento a alguém que, não sendo o pai biológico, também não deseja ser pai sócio-afetivo. A contrário sensu, se o afeto persiste deforma que pais e filhos constroem uma relação de mútuo auxílio, respeito e amparo, é acertado desconsiderar o vínculo meramente sanguíneo, para reconhecer a existência de filiação jurídica. Recurso conhecido e provido (BRASIL, 2006).

Destarte, a paternidade socioafetiva não afasta o direito ao reconhecimento do vínculo biológico, conforme aponta Velloso (2017):

[...] existem cada vez mais decisões e posicionamentos jurídicos recentes, inclusive de tribunais superiores, que vêm mostrando a mitigação do absolutismo da irrevogabilidade do reconhecimento da paternidade socioafetiva em casos que um filho queira ter o reconhecimento de seu vínculo biológico registrado legalmente mesmo que conste um registro de pai socioafetivo, há precedente jurídico que o ampare e, caso a caso, faça não prevalecer a filiação socioafetiva frente a filiação biológica”. O posicionamento do Superior Tribunal de Justiça, através de uma de suas Turmas, no que diz respeito ao fato de que a filiação socioafetiva não é impedimento para o reconhecimento do vínculo biológico vem reafirmar que não pode a lei ou a doutrina obstaculizar a análise e a possibilidade de uma decisão favorável à desconstituição da paternidade socioafetiva quando visar o melhor interesse do filho (VELLOSO, 2017).

Materializando o conceito exposto acima por Velloso (2017) se tem o agravo regimental neste caminho:

AGRAVO REGIMENTAL NO AGRAVO EM RECURSO ESPECIAL. INVESTIGAÇÃO DE PATERNIDADE. VIOLAÇÃO AO ART. 535 DO CPC. INEXISTÊNCIA. PATERNIDADE SOCIOAFETIVA. IMPEDIMENTO PARA O RECONHECIMENTO DA PATERNIDADE BIOLÓGICA. NÃO OCORRÊNCIA. AÇÃO PROPOSTA PELO FILHO. AGRAVO NÃO PROVIDO. 1. Não se constata violação ao art. 535 do CPC quando a col. Corte de origem dirime, fundamentadamente, todas as questões que lhe foram submetidas. Havendo manifestação expressa acerca dos temas necessários à integral solução da lide, ainda que em sentido contrário à pretensão da parte, fica afastada qualquer omissão, contradição ou obscuridade. 2. A existência de relação socioafetiva com o pai registral não impede o reconhecimento dos vínculos biológicos quando a investigação de paternidade é demandada por iniciativa do próprio filho, uma vez que a pretensão deduzida fundamentase no direito personalíssimo, indisponível e imprescritível de conhecimento do estado biológico de filiação, consubstanciado no princípio constitucional da dignidade da pessoa humana (CF, art. $1^{\circ}$, III). Precedentes. 3. Agravo regimental a que se nega provimento. (BRASIL, 2015)

Com efeito, os julgados apresentados demonstram que tanto doutrina quanto a jurisprudência percebem que a filiação socioafetiva não pode ser excluída do rol do Direito de Família, representando um importante viés jurídico nas relações sociais e de família no cenário contemporâneo, bem como para o Direito sucessório, como se observa no julgado abaixo:

APELAÇÃO CÍVEL. DIREITO DE FAMÍLIA. DIREITO CONSTITUCIONAL. DIREITO PROCESSUAL CIVIL. AÇÃO DE INVESTIGAÇÃO DE PATERNIDADE SOCIOAFETIVA POST MORTEM. INEXISTÊNCIA DE PAI REGISTRAL/BIOLÓGICO. EXISTÊNCIA DE RELAÇÃO PATERNO-FILIAL QUE CARATERIZA A PATERNIDADE SOCIOAFETIVA. INCLUSÃO DO NOME PATERNO. ANULAÇAO DE ESCRITURA PÚBLICA DE INVENTARÁRIO E PARTILHA. RECURSOS CONHECIDOS E NÃO PROVIDOS. SENTENÇA MANTIDA. 1. Os apelantes pretendem a modificação da $\mathrm{r}$. sentença da instância a quo para que seja julgado improcedente o pedido de reconhecimento de paternidade socioafetiva e, por consequência seja declarada a legalidade da partilha dos bens anteriormente registrada. 2. Os adquirentes dos direitos sobre o imóvel, objeto do pedido de anulação da Escritura Pública de Inventário e Partilha, alegam, em sede preliminar, a ilegitimidade passiva, sob entendimento de não ser possível incluir o espólio no pólo passivo, mas somente os herdeiros. A preliminar não merece prosperar em virtude da superveniência de fato modificativo do direito que pode influir no julgamento da lide, conforme art. 462 do Código de Processo Civil, com a possibilidade da ocorrência da eviç̧ão. 3. A paternidade socioafetiva é construção recente na doutrina e na jurisprudência pátrias, segundo o qual, mesmo não havendo vínculo biológico alguém educa uma criança ou adolescente por mera opção e liberalidade, tendo por fundamento o afeto. Encontra guarida na Constituição Federal de $1988, \S 4^{\circ}$ do art. 226 e no $\S 6^{\circ}$ art. 227 , referentes aos direitos de família, sendo proibidos quaisquer tipos de discriminações entre filhos. 4. A jurisprudência, mormente na Corte Superior de Justiça, já consagrou o entendimento quanto à plena possibilidade e validade do estabelecimento de paternidade/maternidade socioafetiva, devendo prevalecer a paternidade socioafetiva para garantir direitos aos filhos, na esteira do princípio do melhor interesse da prole. 5. No caso dos autos resta configurado o vínculo socioafetivo entre as partes, que se tratavam mutuamente como pai e filho, fato publicamente reconhecido por livre e espontânea vontade do falecido, razão pela qual deve prevalecer o entendimento firmado na sentença quanto à declaração do vínculo paternofilial, resguardando-se os direitos sucessórios decorrentes deste estado de filiação, e respectiva anulação da Escritura Pública de Inventário e Partilha anteriormente lavrada. 6. Recursos conhecidos e não providos. Sentença mantida integralmente.

Demonstra-se evidente ante aos estudos aqui apresentados que como descreve Lôbo (2017): "muito se avançou no Brasil no que a doutrina jurídica especializada denomina paternidade (e filiação) socioafetiva, entendida como a que se constitui na convivência familiar, independentemente da origem do filho."

Dias (2015, p. 72) menciona que: "o atual princípio norteador do direito de família é o princípio da afetividade, posto que é atribuído valor jurídico ao afeto", o que implica diretamente nas decisões e nos critérios utilizados para consubstanciar as decisões, sejam essas judiciais ou extrajudiciais e de caráter conciliatório.

Vê-se, portanto, ao longo das últimas décadas, o debruçar da doutrina para distinguir o que seja um genitor de um pai. Assim, Lôbo (2017, p.2) destaca que: 
Pai é o que cria. Genitor é o que gera. Esses conceitos estiveram reunidos, enquanto houve primazia da função biológica da família. Afinal, qual a diferença razoável que deva haver, para fins de atribuição de paternidade, entre o homem dador de esperma, para inseminação heteróloga, e o homem que mantém uma relação sexual ocasional e voluntária com uma mulher, da qual resulta concepção? Tanto em uma como em outra situação, não houve intenção de constituir família. Ao genitor devem ser atribuídas responsabilidades de caráter econômico, para que o ônus de assistência material ao menor seja compartilhado com a genitora, segundo o princípio constitucional da isonomia entre sexos, mas que não envolvam direitos e deveres próprios de paternidade.

A paternidade se configura como complexa e vai além do provimento de alimentos ou de direitos sucessórios, envolvendo afeto, valores, convivência familiar, cuidado, respeito e tudo o mais o que prega a Constituição Federal no que tange à dignidade da pessoa humana e no que tange aos Direitos Fundamentais, sendo entre esses o direito: “à vida, à saúde, à alimentação, à educação, ao lazer, à profissionalização, à cultura, à dignidade, ao respeito, à liberdade e à convivência familiar" (BRASIL, 1988).

Nessa perspectiva, considera-se pai aquele que assume esses deveres, ainda que não seja o genitor biológico.

A filiação socioafetiva é vista como uma construção da realidade fática, pois pai não é apenas aquele que transmite a carga genética, é também aquele que exerce tal função no cotidiano.

Corrobora-se com o citado acima, o Recurso Especial abaixo:

PROCESSUAL CIVIL. CIVIL. RECURSO ESPECIAL. REGISTRO CIVIL. ANULAÇÃO PEDIDA POR PAI BIOLÓGICO. LEGITIMIDADE ATIVA. PATERNIDADE SOCIOAFETIVA. PREPONDERÂNCIA. 1. A paternidade biológica não tem o condão de vincular, inexoravelmente, a filiação, apesar de deter peso específico ponderável, ante o liame genético para definir questões relativas à filiação. 2 . Pressupõe, no entanto, para a sua prevalência, da concorrência de elementos imateriais que efetivamente demonstram a ação volitiva do genitor em tomar posse da condição de pai ou mãe. 3. A filiação socioafetiva, por seu turno, ainda que despida de ascendência genética, constitui uma relação de fato que deve ser reconhecida e amparada juridicamente. Isso porque a parentalidade que nasce de uma decisão espontânea, frise-se, arrimada em boa-fé, deve ter guarida no Direito de Família. 4. Nas relações familiares, o princípio da boa-fé objetiva deve ser observado e visto sob suas funções integrativas e limitadoras, traduzidas pela figura do venire contra factum proprium (proibição de comportamento contraditório), que exige coerência comportamental daqueles que buscam a tutela jurisdicional para a solução de conflitos no âmbito do Direito de Família. 5. Na hipótese, a evidente má-fé da genitora e a incúria do recorrido, que conscientemente deixou de agir para tornar pública sua condição de pai biológico e, quiçá, buscar a construção da necessária paternidade socioafetiva, toma-lhes o direito de se insurgirem contra os fatos consolidados. 6. A omissão do recorrido, que contribuiu decisivamente para a perpetuação do engodo urdido pela mãe, atrai o entendimento de que a ninguém é dado alegrar a própria torpeza em seu proveito (Nemo auditur propriam turpitudinem allegans) e faz fenecer a sua legitimidade para pleitear o direito de buscar a alteração no registro de nascimento de sua filha biológica.7. Recurso especial provido.
Por derradeiro, o Poder Judiciário tem reconhecido a paternidade most mortem, o que realça a importância do instituto jurídico para o Direito de Família e das Sucessões (ação judicial imprescritível). Seguem recentes decisões:

APELAÇÃO CÍVEL. AÇÃO DE RECONHECIMENTO JUDICIAL DE MATERNIDADE SOCIOAFETIVA CUMULADO COM PETIÇÃO DE HERANÇA. INDEFERIMENTO DA INICIAL PELA AUSÊNCIA DE INTERESSE PROCESSUAL. Pleito de desconstituição da sentença. Cabimento. O ordenamento jurídico não veda o pleito de reconhecimento de maternidade/paternidade socioafetiva post mortem, inexistindo, inclusive, a necessidade de ajuizamento prévio de ação de adoção ou manifestação do interesse em testamento para que seja caracterizada a intenção dos de cujus. Além disso, os requisitos caracterizadores da maternidade socioafetiva post mortem podem ser demonstrados através de prova oral, não necessitando, obrigatoriamente, de documento formal com a expressa vontade das partes, o que enseja o prosseguimento do feito, estando plenamente demonstrado o interesse processual. Apelação provida. Sentença desconstituída. (TJRS; APL 0232964-91.2019.8.21.7000; Proc 70082610551; Pelotas; Oitava Câmara Cível; Rel. Des. José Antônio Daltoe Cezar; Julg. 28/05/2020; DJERS 16/09/2020)

APELAÇÃO CÍVEL. AÇÃO DECLARATÓRIA DE PATERNIDADE SOCIOAFETIVA POST MORTEM. SENTENÇA DE EXTINÇÃO DO FEITO, SEM JULGAMENTODEMÉRITO. Desconstituição. Cerceamento de defesa caracterizado. Reconhecimento do direito da parte de produzir as provas destinadas a comprovar as relações socioafetivas narradas na petição inicial. Precedentes desta corte e dos tribunais superiores. Apelo provido. (TJRS; APL 0004183-09.2020.8.21.7000; Proc 70083658245; Santa Cruz do Sul; Sétima Câmara Cível; Rel ${ }^{\mathrm{a}} \mathrm{Des}^{\mathrm{a}}$ Sandra Brisolara Medeiros; Julg. 25/06/2020; DJERS 08/09/2020)

APELAÇÃO. PATERNIDADE SOCIOAFETIVA POST MORTEM. AÇÃO PROPOSTA QUANDO JÁ FALECIDA COM 20 ANOS A PESSOA CUJA FILIAÇÃO SE QUER VER RECONHECIDA. Possibilidade. Prova dos autos comprova a relação socioafetiva entre os autores/apelantes e a falecida. Genitora faleceu após o parto. Genitor em local incerto e não sabido. Criança veio morar com os autores/ apelantes desde que nasceu e assim ficou até falecer com 20 anos de idade. Eventual quantia a ser levantada em nome de M.L.S. Configura apenas efeito acessório do reconhecimento da paternidade socioafetivo e não pode servir para impedir a pretensão. Sentença reformada. Recurso Provido. (TJSP; AC 1001743-85.2018.8.26.0361; Ac. 13801915; Mogi das Cruzes; Terceira Câmara de Direito Privado; Rel. Des. Beretta da Silveira; Julg. 29/07/2020; DJESP 04/08/2020; Pág. 1616, grifo nosso)

\section{Conclusão}

Aduz a própria Constituição Federal no Art. 226 que a família é o alicerce da sociedade e, sendo a sociedade dinâmica, permeada por relações sociais, políticas e econômicas se faz decisivo o acompanhamento da legislação e das reflexões em torno do Direito de Família para dar conta de responder às demandas contemporâneas.

Nessa onda evolutiva é perceptível a incorporação dos princípios dos Direitos Humanos pelo Direito de Família, que passa a considerar os indivíduos em suas mais diversas formas de manifestação, o qual zela por seus interesses individuais, e que passam a ser amparados pelo ordenamento jurídico 
brasileiro, tanto quanto os coletivos, configurando assim uma nova era do Direito de Família, principalmente, no que tange às questões subjetivas relacionadas ao afeto, considerado o ponto focal da formação familiar.

Como mencionado alhures, a filiação socioafetiva encontrou amparo na Constituição Federal de 1988, passando a ampliar as ramificações e concepções de família, encontrando igual apoio no Código Civil nos Art. 1.593 e 1.596, sendo assim, consagrada juridicamente no ordenamento jurídico brasileiro.

Em que pese haja segurança jurídica na adoção desta prática, no cotidiano, a filiação socioafetiva ainda causa dúvidas e controvérsias ideológicas, as quais nos últimos anos têm sido alvo de avanços e retrocessos, como todo bom processo de evolução na sociedade.

Consoante demonstrado, o Poder Judiciário tem reconhecido a paternidade socioafetiva, com o significado mais profundo que o proporcionado a paternidade biológica, o qual preserva e reforça o princípio da dignidade da pessoa humana e os direitos fundamentais.

Ainda que a lei deixe existirem lacunas em torno da temática, a doutrina e a jurisprudência vêm se aperfeiçoando no reconhecimento desta modalidade de filiação, conferindo para aqueles cujos requisitos legais sejam preenchidos, o estado de filho, a transferência de bens e direitos, bem como seus encargos e obrigações, quando da abertura da sucessão, no caso de enquadramento como herdeiro, conforme ordem de sucessão hereditária.

\section{Referencias}

ALMEIDA, G.W.G. Evolução histórica do direito de família no ordenamento jurídico brasileiro. Conteúdo Jurídico, 2015. Disponível em: http://www.conteudojuridico.com. br/?artigos\&ver=2.44723\&seo=1. Acesso em: 25 set 2020 .

ANDRADE, E.C.C. Filiação socioafetiva. Ambito Jurídico, n.130, 2014. Disponível em: http://www.ambito-juridico.com.br/ site/?n_link=revista_artigos_leitura\&artigo_id $=15458$. Acesso em: 25 ser. 2020.

BRASIL. Constituição da República Federativa do Brasil. Brasília: Senado, 1988.

BRASIL. Conselho Nacional De Justiça. Provimento $n^{0} 63$, de 14 de novembro de 2017. Disponível em: http://www.cnj.jus.br/ busca-atos-adm?documento=3380. Acesso em: 25 set. 2020 .

BRASIL. Lei n. ${ }^{o} 10.406$, de 10 de janeiro de 2002. Código Civil Brasileiro. Brasília: Senado, 2002.

CARVALHO, D.M. Direito de Família: direito civil. Belo Horizonte: Del Rey, 2017.

COSTA, T.M.M.L. Adoção por pares Homoafetivos: uma abordagem jurídica e psicológica. 2017. Disponível em: http:// www.viannajr.edu.br/revista/dir/doc/art_10005.pdf. Acesso em: 25 set. 2020.

DIAS, M.B. Manual de Direito das Famílias. São Paulo: Revista dos Tribunais, 2015.

DINIZ, M.H. Curso de Direito Civil Brasileiro. São Paulo: Saraiva, 2017.

FARIAS, C.C.; ROSENVALD, N. Curso de Direito Civil-Parte Geral e LINDB. Salvador: JusPODIVM, 2012.

GONÇALVES, C.R. Direito civil brasileiro: direito de família. São Paulo: Saraiva, 2012.

LÔBO, P. Direito Civil - Famílias. São Paulo: Saraiva, 2017.

MACEDO, S.C.A. Adoção por parceria homoafetiva e seus reflexos no âmbito jurídico. Campina Grande: Universidade da Paraíba, 2012.

MARCONI, M.A.; LAKATOS, E.M. Metodologia do trabalho científico. São Paulo: Atlas, 1992.

NOGUEIRA, M.B. A família: conceito e evolução histórica e sua importância. 2015. Disponível em: http://www.egov.ufsc.br/ portal/sites/default/files/anexos/18496-18497-1-PB.pdf. Acesso em: 25 set. 2020.

OLIVEIRA, B.P.M. A impossibilidade da desconstituição da paternidade socioafetiva. Uberlândia: Universidade Federal de Uberlândia, 2018.

PEREIRA, R.C. Famílias ensambladas e parentalidade socioafetiva- a propósito da sentença do tribunal constitucional, de 30.11.2007. Rev. Magister Direito Fam. Sucessões., v.7, p.8894, 2016.

PEREIRA, R.C. Direito de Família: uma abordagem psicanalítica. Belo Horizonte: Del Rey, 2013.

RIBEIRO, A.V. A evolução do casamento e seus efeitos jurídicos: uma demonstração da evolução do casamento e seus efeitos jurídicos: desde o passado até os dias atuais. 2014. Disponível em: $<$ https://monografias.brasilescola.uol.com. br/direito/a-evolucao-casamento-seus-efeitos-juridicos.htm>. Acesso em: 25 set. 2020.

SANTOS, R.M.M. Um novo paradigma jurídico sobre família. 2017. Disponível em: http://www6.univali.br/tede/tde_busca/ arquivo.php? codArquivo=247. Acesso em: 25 set. 2020 .

SOUZA, C.M.A. CNJ cria regras para reconhecimento extrajudicial de filiação socioafetiva. 2017. Disponível em: https://www.conjur.com.br/2017-dez-03/carlos-souza-cnjcria-regras-reconhecer-filiacao-socioafetiva. Acesso em: 25 set. 2020.

TARTUCE, F. Direito Civil, v.5: Direito de Família. Rio de Janeiro: Forense, 2017.

TARTUCE, F. Manual de Direito Civil. Rio de Janeiro: Método, 2016.

VELLOSO, R. Reconhecimento da paternidade socioafetiva. 2017. Disponível em: http://reinaldovelloso.blog.br/?p=667. Acesso em: 25 set. 2020. 
